\title{
Behavior of Dioxin Like PCBs and PBDEs During Early Diagenesis of Organic Matter in Settling Material and Bottom Sediments from the Sewage Impacted Buenos Aires' Coastal Area, Argentina
}

\author{
N. Cappelletti $\cdot$ C. N. Skorupka $\cdot$ M. C. Migoya \\ L. Tatone $\cdot$ M. Astoviza $\cdot$ J. C. Colombo
}

Received: 29 November 2013/Accepted: 23 July 2014/Published online: 31 July 2014

(C) Springer Science+Business Media New York 2014

\begin{abstract}
Settling particles (SPs) and sediments collected in the Buenos Aires sewer area were analyzed for dioxin like polychlorinated biphenyls (dlPCBs) and polybrominated diphenyl ethers (PBDEs) to follow early diagenetic changes during transport and deposition of organic matter. SP showed a temporal trend of higher total organic carbon (TOC) and fresher dIPCBs and PBDEs signatures during warm-rainy months related to more efficient washout of residues. TOCnormalized sediment trap concentrations suggest a diagenetic magnification of dIPCBs during cold-dry months due to enhanced decomposition of TOC, whereas most labile PBDEs appear to follow TOC decay. The diagenetic behavior of individual congeners along seasonal changes (cold/warm) and during deposition (bottom sediment/SP) shows the selective preservation of heavier, more persistent congeners with a positive relationship with sediment halflives. The 3-4 times diagenetic magnification of heavier congeners observed in bottom sediments would be a prevailing long-term pathway for dIPCBs and PBDEs bioaccumulation in detritus feeding organisms.
\end{abstract}

N. Cappelletti $(\bowtie) \cdot$ C. N. Skorupka $\cdot$ M. C. Migoya ·

L. Tatone - M. Astoviza - J. C. Colombo

Laboratorio de Química Ambiental y Biogeoquímica, Facultad

de Ciencias Naturales y Museo, Universidad Nacional de La

Plata, Av. Calchaqui km 23500, 1888 Florencio Varela,

Buenos Aires, Argentina

e-mail: laqab@fcnym.unlp.edu.ar;

ncappelletti.laqab@gmail.com

N. Cappelletti - M. C. Migoya - L. Tatone - M. Astoviza Consejo Nacional de Investigaciones Científicas y Técnicas, Buenos Aires, Argentina

J. C. Colombo

Comisión de Investigaciones Científicas, Provincia de Buenos

Aires, Buenos Aires, Argentina
Keywords Dioxin like PCB - PBDE - Rio de la Plata · Vertical fluxes $\cdot$ Diagenetic $\cdot$ Sewage

Persistent organic pollutants (POPs) are ubiquitous hydrophobic contaminants in aquatic ecosystems which adsorb to suspended particles and selectively survive degradative processes during vertical transport and deposition (de Bruyn and Gobas 2004). Among polychlorinated biphenyls (PCBs), the most toxic subset of 12 non-ortho and mono-ortho dioxin like PCBs congeners (dlPCBs: toxicity $\sim 2,3,7,8$-tetrachlorodibenzo- $p$-dioxin) have been included in an equivalent toxicity scheme that allows the calculation of total equivalent toxicity (TEQ; Safe 1992; Van den Berg et al. 1998), but their detailed environmental behavior along diagenetic processes is poorly documented. Polybrominated diphenyl ethers (PBDEs) used as additive flame retardants in commercial and household products (Alaee et al. 2003) share some chemical characteristics with PCBs (i.e., hydrophobicity), but they are somewhat less persistent and have a more recent concerns (Vonderheide et al. 2008), and like dlPCBs, information on their diagenetic transformation is scarce (i.e., Johannessen et al. 2008; Salvadó et al. 2012).

The Rio de la Plata is a turbid coastal plain estuary with a total surface area of $35,000 \mathrm{~km}^{2}$ and a huge particulate load (90 million tons for year). The upper freshwater sector in front of Buenos Aires City receives untreated effluents from the main sewer $\left(\sim 2\right.$ million $\mathrm{m}^{3}$ day $^{-1}$; Cirelli and Ojeda 2008) and several polluted channels and ports. The high natural particulate load of the system combined to the anthropogenic discharges produce large vertical fluxes of pollutants that are deposited in bottom sediments (Colombo et al. 2005a, b, 2007), facilitating their bioaccumulation by dominant detritus feeding fish (Colombo et al. 2011). 


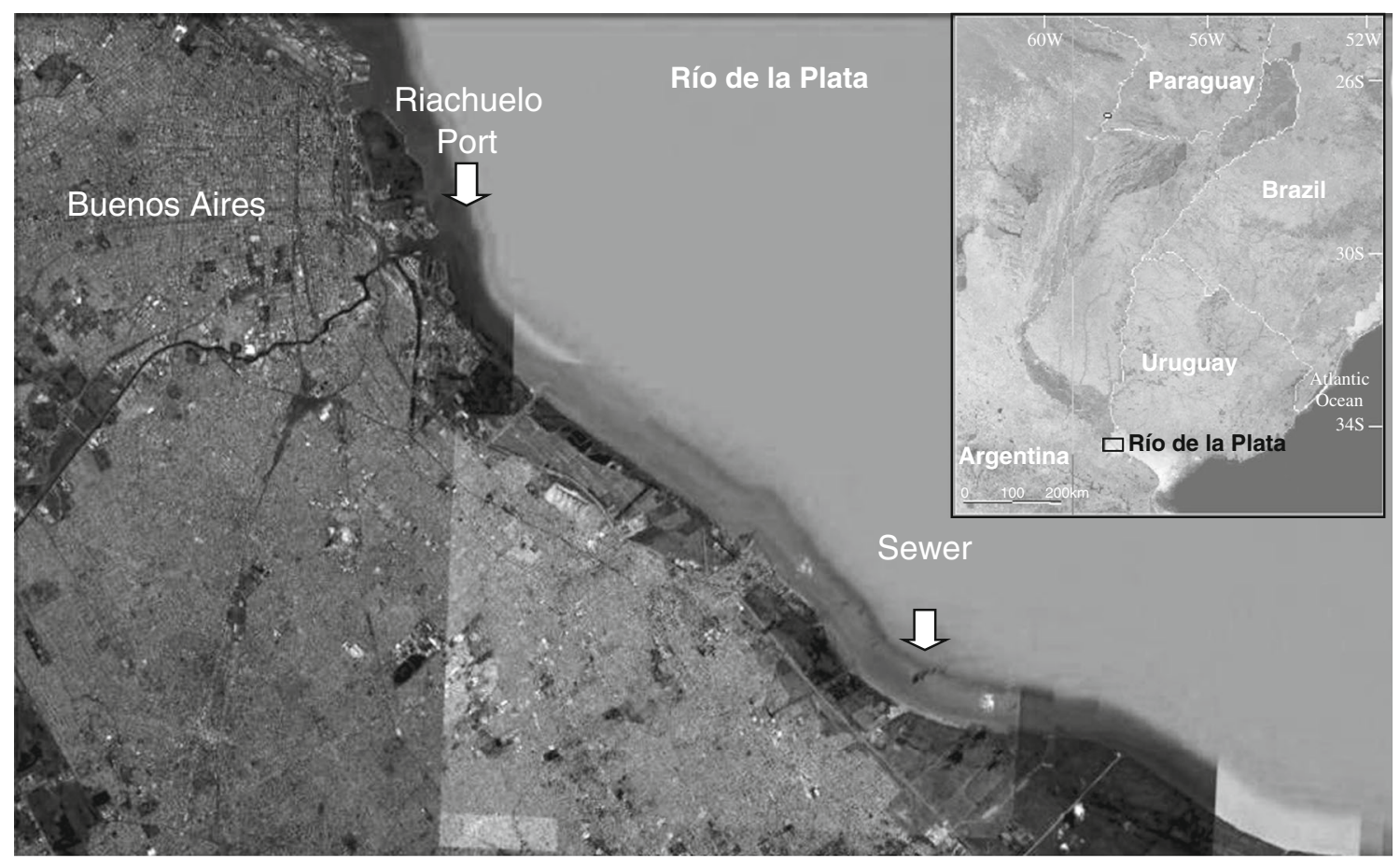

Fig. 1 Study area in the Metropolitan Buenos Aires coast (based on Google Earth 6.1.5001).The arrows indicate the Riachuelo Port and sewer

In order to more precisely evaluate the impact of these pollutants in this temperate freshwater ecosystem, we explore the effect of early diagenetic alteration of organic matter on dIPCBs and PBDEs signatures, the selective magnification of congeners in bottom sediments and their potential bioavailability.

\section{Methods}

Settling particles (SP) were collected in the coastal area of Buenos Aires (Fig. 1), $1.5 \mathrm{~m}$ below the surface in a 5-6 m water column with two fixed $10 \mathrm{~cm}$-diameter sediment traps deployed upstream and downstream the sewer for 20-48 h (13 deployments).Superficial sediments $(n=7)$ were collected in the sewer area with a "Van Veen" style Hydro-Bios stainless steel grab sampler.

SP were immediately centrifuged and subsamples were taken for total organic carbon (TOC) and Nitrogen analysis (Catalytic combustion with Thermo Finnigan, CE Flash EA 1112 elemental analyzer), and for the determination of trace organics. Sediments were split into subsamples for grain size analysis (sieve and pipet method), for TOC analysis, and for the determination of trace organics. Samples were spiked with internal standards (PCBs 103 and 198; Absolute Standard), and ultrasonically extracted with acetone: dichloromethane: petroleum ether $(1: 2: 2)$. The extracts were concentrated under nitrogen, treated with activated copper and fractionated by chromatography on silica gel to separate PCBs (petroleum ether) and PBDEs (petroleum etherdichloromethane). Ortho PCBs (petroleum ether: dichloromethane), mono-ortho PCBs (dichloromethane: toluene) and non-ortho PCBs (toluene) were fractionated by additional clean up on carbon-impregnate silica gel columns.

Dl PCBs were quantified by high resolution gas chromatography (GC Agilent 6890 and 6850) using DB 5 MS columns and equipped with a ${ }^{63} \mathrm{Ni}$ electron capture detector (mono ortho PCBs) and mass spectrometer (5973N) used to confirm mono-ortho PCBs and mandatory to quantify nonortho PCBs. The mass detector was operated in SIM mode at $\mathrm{m} / \mathrm{z}, 290$ and 292, 324 and 326, 354 and 358, and 392 and 394 to identify tetra-, penta-, hexa-, and hepta- CBs, respectively. Quantification was performed using an external standard of 28 congeners (Accustandard C-WNN; 5 point calibration curve). PBDEs were analyzed by high resolution gas chromatography/mass spectrometry using negative chemical ionization mode (Perkin Elmer Clarus $500)$ in simultaneous scan $(\mathrm{m} / z, 70-700)$ and SIM modes $(\mathrm{m} / \mathrm{z}, 79$ and 81$)$ and a $30 \mathrm{~m}$ DB $5 \mathrm{MS}$ column. Quantification was done with an external standard of 39 PBDEs (Accustandard BDE-AAP-A; 4 point calibration curve).

The detection limits (3:1 signal to noise) ranged from 4 to $19 \mathrm{pg} \mathrm{g}^{-1} \mathrm{dw}$ for dlPCBs and 2-6 $\mathrm{pg} \mathrm{g}^{-1} \mathrm{dw}$ for PBDEs. The quantification limits (10:1 signal to noise) ranged from 13 to $60 \mathrm{pg} \mathrm{g}^{-1} \mathrm{dw}$ for dlPCBs and $7-20 \mathrm{pg} \mathrm{g}^{-1} \mathrm{dw}$ for PBDEs. Procedural blanks (one for every batch of twelve 
samples) were below the detection limits and surrogate recovery ranged between 60 and $110 \%$.

Total equivalent toxicity (TEQ) was calculated using World Health Organization factors for dIPCBs (Van den Berg et al. 1998) and compared to Canadian Sediment Quality Guidelines (CSQG; CCME 2001).

Concentrations of dlPCBs and PBDEs are expressed in dry weight $(\mathrm{dw})$ or TOC-normalized as indicated. Upstream and downstream dIPCBs and PBDEs concentrations for the same sampling day were averaged since they showed no significant differences ( $t$ test; $p>0.05$ ). PBDEs data were only available for 7 trap deployments and 4 bottom sediment samples. Fluxes were calculated with the total mass sedimentation $\left(\mathrm{g} \mathrm{m}^{-2} \mathrm{day}^{-1}\right)$ and the dry weight concentration of pollutants in settling particles.

\section{Results and Discussion}

In SP $\Sigma$ dlPCBs ranged from $0.60-14 \mathrm{ng} \mathrm{g}^{-1} \mathrm{dw}$ (mean \pm standard deviation: $6.0 \pm 3.6 \mathrm{ng} \mathrm{g}^{-1} \mathrm{dw}$ ), similar to values reported for settling matter from the Detroit (Marvin et al. 2002) and Niagara River (Marvin et al. 2007), and one order of magnitude lower than values reported for the impacted Trenton Channel (Marvin et al. 2002). The total equivalent toxicity of dIPCBs calculated for the SP ranged from 0.3 to $18 \mathrm{pg}$ TEQ $\mathrm{g}^{-1} \mathrm{dw}\left(4.3 \pm 4.3 \mathrm{pg}\right.$ TEQ $\left.\mathrm{g}^{-1} \mathrm{dw}\right)$, principally attributable to non-ortho CB $126(60 \% \pm 24 \%)$ and mono-ortho CBs 156 and $118(25 \% \pm 20 \%$ and $18 \% \pm 14 \%$, respectively).Three of the thirteen traps exceeded the CSQG threshold effect level $\left(\right.$ TEL $\left.=0.85 \mathrm{pgTEQ} \mathrm{g}^{-1}\right)$. $\Sigma$ PBDEs concentrations in SP ranged from 1.0 to $3.0 \mathrm{ng} \mathrm{g}^{-1} \mathrm{dw}$ $\left(2.2 \pm 0.59 \mathrm{ng} \mathrm{g}^{-1} \mathrm{dw}\right)$, comparable to reports for suspended sediment from a non-impacted area of Lake Erie (Marvin et al. 2007), and lower than values published for the Niagara River (Marvin et al. 2007), and the Rhine River Delta near industrialized and urbanized areas (de Boer et al. 2003).

The vertical fluxes, calculated from the massive total sediment mass collected by the traps (175-673 $\mathrm{g} \mathrm{m}^{-2}$ day $^{-1}$ ) and moderate concentrations of AlPCBs and PBDEs of the particles, are very high reflecting anthropogenic discharges but also the natural high turbidity of the estuary mainly derived from rainy Andean food plains (Drago and Amsler 1988). The average flux of dlPCBs $\left(2.5 \pm 2.2 \mu \mathrm{g} \mathrm{m}^{-2}\right.$ $\mathrm{day}^{-1}$ ) is two orders of magnitude higher than values calculated from sediment cores collected in Lake Suwa, Japan (Ikenaka et al. 2005). Converted to total equivalent toxicity, the TEQ fluxes averaged $1.7 \pm 1.7 \mathrm{ng} \mathrm{m}^{-2}$ day $^{-1}$.The flux of PBDEs $\left(1.0 \pm 0.61 \mu \mathrm{g} \mathrm{m}^{-2}\right.$ day $\left.^{-1}\right)$ is also two orders of magnitude higher than fluxes calculated for Lakes Michigan and Erie (Zhu et al. 2004), and similar to those calculated for the Pearl River Estuary, China (Chen et al. 2007).

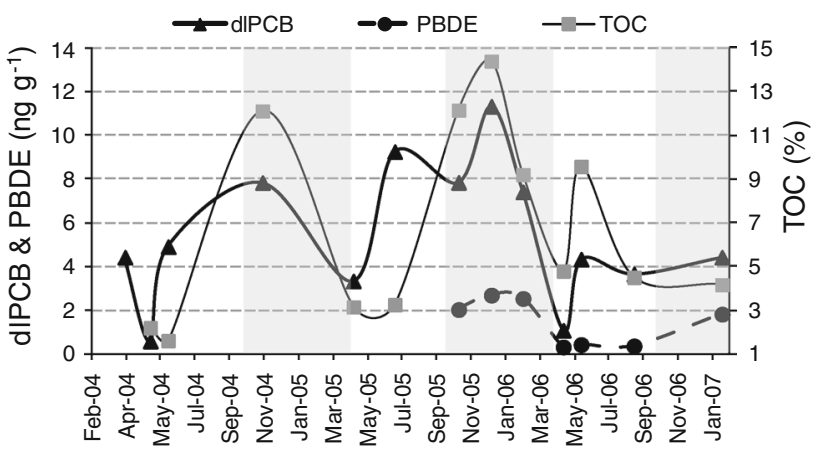

Fig. 2 Total organic carbon (TOC), dlPCBs and PBDEs concentrations in settling particles. Warm-rainy periods are shaded in gray

In spite of this massive vertical transport of pollutants, bottom sediments (76\% $\pm 5 \%$ silt) contained four times lower TOC contents relative to SP $(1.8 \% \pm 0.9 \%$ vs. $7.2 \% \pm 5.4 \%$ ), and approximately half dIPCBs and PBDEs dry weight concentrations, denoting a strong alteration of organic matter. $\Sigma$ dlPCBs ranged from 1.4 to $8.0 \mathrm{ng} \mathrm{g}^{-1} \mathrm{dw}\left(3.5 \pm 2.1 \mathrm{ng} \mathrm{g}^{-1} \mathrm{dw}\right)$, similar to sediments from the Han River, Korea (Kim et al. 2009) and from Lake Superior affected by industrial activities (Shen et al. 2009). The average TEQconcentration in sediments decrease six times relative to SP $(0.7 \pm 0.3$ vs. $4.3 \pm 4.3 \mathrm{pg}^{\mathrm{TEQ}} \mathrm{g}^{-1} \mathrm{dw}$ ), basically due to the10-times decrease of non-ortho tetraCB $126(76 \% \pm 6 \%)$; two of the seven sediment samples exceeded the TEL. PBDEs concentrations in bottom sediments ranged from 0.5 to $1.5 \mathrm{ng} \mathrm{g}^{-1} \mathrm{dw}\left(1.0 \pm 0.4 \mathrm{ng} \mathrm{g}^{-1} \mathrm{dw}\right)$, comparable to values reported for Lake Superior (Song et al. 2004) and for the Pearl River Delta, South China (Zheng et al. 2004), and one order of magnitude lower than impacted sediments from the Cinca River, Spain (Eljarrat et al. 2004), and the Masan Bay, Korea (Moon et al. 2008).

Figure 2 presents the seasonal variation of TOC, $\Sigma$ dlPCBs and $\Sigma$ PBDEs in the SP. Compared with autumnwinter traps, particles collected in spring and summer months contain about twice of the TOC, dlPCBs, PBDEs. This seasonal cold-warm difference is related to the stronger anthropogenic pulses of TOC and organic pollutants in the warm-rainy period (November-March), when the trap material presents higher concentrations and fresh contaminant signatures due to a more efficient washout of waste from Buenos Aires Port and polluted channels (Colombo et al. 2007).

In order to evaluate the individual congener behaviour during the decay of organic matter, a comparison was performed for early (temporal variability of traps) and more advanced diagenetic stages (incorporation to bottom sediments). The early stage evaluation was performed considering the ratios of average TOC normalized concentrations of individual congeners between cold 

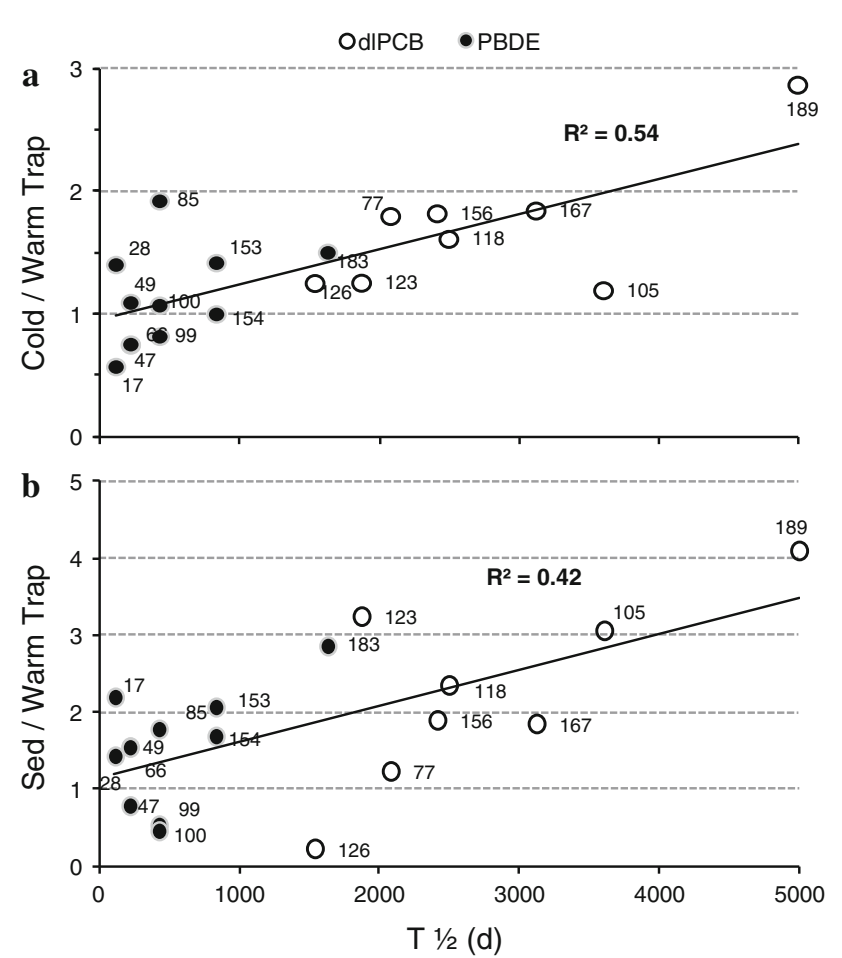

Fig. 3 Diagenetic magnification ratios of individual dlPCB and PBDE congeners in earlier (a cold/warm traps) and later stages of organic matter decomposition (b sediment/warm traps) plotted against half lives in sediments

(degraded)/warm (fresher) sediment traps. The more advanced stage was tested by bottom sediment/traps average TOC normalized concentration ratios. Figure 3 presents cold/warm traps and sediment/trap ratios plotted against dlPCBs and PBDEs half-lives in sediments obtained from Paasivirta and Sinkkonen (2009) or calculated according to Arnot et al. (2005) (EPIWin suite 4.1; USEPA 2011).

The data in Fig. 2 suggests that seasonal TOC normalized trap concentrations are not significantly different, but insinuate a $\Sigma$ dlPCBs increase in the more degraded autumn-winter traps. This suggests the possible diagenetic magnification of dIPCBs related to the faster decomposition of TOC as observed by de Bruyn and Gobas (2004). An enhanced adsorption of pollutants at lower winter temperatures (Della Site 2001) could also contribute to this increase. In contrast, the most labile PBDEs appear to follow TOC decay. The plot of individual congener cold/ warm traps ratios versus half-lives $\left(\mathrm{T}^{1 / 2}\right)$ confirms that the decay difference is congener specific. Overall, a positive correlation is observed between the ratios and $\mathrm{T}^{1 / 2}$ with more persistent dlPCBs congeners exhibiting a significant magnification, whereas shorted lived PBDEs show ratios closer to one. The ratios indicate a depletion of more labile ( $\mathrm{T}^{1 / 2}<1,000$ days) PBDEs such as BDE 17, 47 and 99 in cold traps (cold/warm ratios: $0.6 ; 0.8 ; 0.8)$, suggesting that they decompose at a rate faster than TOC. Although congeners 28,49 and 85 present relatively low $\mathrm{T}^{1 / 2}(109$, 215 and 423 days), they exhibit relatively high cold/warm ratios (1.4, 1.1 and 1.9 respectively), indicating a lower degradation rate or most probably their production from higher brominated congeners, i.e. BDE 153, 99 and 47 (Robrock and Korytár 2008; Torkaz III et al. 2008). Heavier, more recalcitrant congeners (CB 189; BDE 183) show the highest ratios (cold/warm: 2.9, 1.5), consistent with their longer half-lives (5,000 and 1,628 days, respectively), and indicating their selective preservation during TOC decay.

In the more advanced digenetic stage during incorporation of SP to bottom sediments (four-times TOC reduction), the mean TOC normalized concentrations double in sediments relative to SP ( $\Sigma$ dlPCBs: $185 \pm 54$ vs. $104 \pm 82$; $\Sigma$ PBDEs: $59 \pm 19$ vs. $29 \pm 16 \mathrm{ng} \mathrm{g}^{-1}$ TOC).This suggests that the rate of organic carbon decomposition exceeds the combined rate of desorption and degradation of dIPCBs and PBDEs resulting in their diagenetic magnification. The positive relationship between sediment/warm trap average ratios (degraded/fresher signal) and half-lives of dlPCBs and PBDEs congeners (Fig. 3) indicates the magnification of more persistent congeners $\left(\mathrm{T}^{1 / 2}>1,000\right.$ days), such as $\mathrm{CB}$ 189 and BDE 183 (ratios 2.2 and 2.8 respectively), and the enhanced decay of more labile compounds, such as BDE 100, 99 and 47 (sediment/warm trap ratio $0.4 ; 0.5$; and 0.8 respectively). A similar PCB fractionation was observed between suspended particles and sediments (Mackintosh et al. 2006), with lower sediment/particle ratios for less hydrophobic and labile di and tri CBs 16, 18, 32 and 53 compared with more recalcitrant penta, hexa, hepta and octa CBs 110, 149, 153, 180 and 194 (0.05-0.09 vs. 2.5-5.0).

The congener specific diagenetic magnification has important implications for detritus-feeding aquatic organisms:in warm-rainy periods, the exposition to fresh and more toxic mixtures, enriched in less persistent compounds, is facilitated; whereas the 3-4 times diagenetic magnification of heavier congeners observed in bottom sediments constitutes a prevailing long-term pathway for dIPCBs and PBDEs bioaccumulation, yet with a reduced total equivalent toxicity.

\section{References}

Alaee M, Arias P, Sjödin A, Bergman A (2003) An overview of commercially used brominated flame retardants, their applications, their use patterns in different countries/regions and possible modes of release. Environ Int 29:683-689

Arnot JA, Gouin T, Mackay D (2005) Practical methods for estimating environmental biodegradation rates. CEMN Report No. 200503. Tech Rep Environ Can 
CCME, Canadian Council of Ministers of the Environment (2001) Canadian environmental quality guidelines for protection of aquatic life. Polychlorinated dibenzo-p-dioxins and polychlorinated dibenzofurans (PCDD/Fs)

Chen S-J, LuoX-J Lin Z, Luo Y, Li K-C, Peng X-Z, Mai B-X, Ran Y, Zeng EY (2007) Time trends of polybrominated diphenyl ethers in sediment cores from the Pearl River Estuary, South China. Environ Sci Technol 41:5595-5600

Cirelli A, Ojeda C (2008) Wastewater management in Greater Buenos Aires, Argentina. Desalination 218:52-61

Colombo JC, Cappelletti N, Lasci J, Migoya MC, Speranza E, Skorupka CN (2005a) Sources, vertical fluxes and accumulation of aliphatic hydrocarbons in coastal sediments of the Rio de la Plata Estuary, Argentina. Environ Sci Technol 39:8227-8234

Colombo JC, Cappelletti N, Barreda A, Migoya MC, Skorupka CN (2005b) Vertical fluxes and accumulation of PCBs in coastal sediments of the Río de la Plata estuary, Argentina. Chemosphere 61:1345-1357

Colombo JC, Cappelletti N, Speranza E, Migoya MC, Lasci J, Skorupka CN (2007) Vertical fluxes and organic composition of SP from the sewage impacted Buenos Aires coastal area, Argentina. Org Geochem 38:1941-1952

Colombo JC, Cappelletti N, Williamson M, Migoya MC, Speranza E, Sericano J, Muir DCG (2011) Risk ranking of multiple-POPs in detritivorous fish from the Río de la Plata. Chemosphere 83:882-889

de Boer JD, Wester PG, Horst AVD, Leonards PEG (2003) Polybrominated diphenyl ethers in influents, suspended particulate matter, sediments, sewage treatment plant and effluents and biota from the Netherlands. Environ Pollut 122:63-74

de Bruyn AM, Gobas FA (2004) Modelling the diagenetic fate of persistent organic pollutants in organically enriched sediments. Ecol Model 179:405-416

Della Site A (2001) Factors affecting sortion of organic compounds in natural sorbent/water systems and sortion coefficients for selected pollutants. A review. J Phys Chem Data 30(1):187-253

Drago E, Amsler M (1988) Suspended sediment at a cross section of the middle Paraná river: concentration, granulometry and influence of the main tributaries. En: Sediment budgets (Proceedings of teh Porto Alegre Symposium), IAHS publ. no. 174

Eljarrat E, de la Cal A, Raldua D, Duran C, Barceló D (2004) Occurrence and bioavailability of polybrominated diphenyl ethers and hexabromocyclododecane in sediment and fish from the Cinca River, a tributary of the Ebro River (Spain). Environ Sci Technol 38:2603-2608

Ikenaka Y, Eun H, Watanabe E, Kumon F, Miyabara Y (2005) Estimation of sources and inflow of dioxins and polycyclic aromatic hydrocarbons from the sediment core of lake. Environ Pollut 138:529-537

Johannessen SC, Macdonald RW, Wright CA, Burd B, Shaw DP, van Roodselaar A (2008) Joined by geochemistry, divided by history: PCBs and PBDEs in Strait of Georgia sediments. Mar Environ Res 66(Supplement):S112-S120

Kim K-S, Lee SC, Kim K-H, Shim W-J, Hong SH, Choi KH, Yoon JH, Kim J-G (2009) Survey on organochlorine pesticides, $\mathrm{PCDD} / \mathrm{Fs}$, dioxin-like PCBs and HCB in sediments from the Han River, Korea. Chemosphere 75:580-587

Mackintosh CE Maldonado JA, Ikonomou MG, Gobas FAPC (2006) Sorption of phthalate esters and PCBs in a marine ecosystem. Environ Sci Technol 40(11):3481-3488

Marvin C, Alaee M, Painter S, Charlton M, Kauss P, Kolic T, Macpherson K, Takeuchi D, Reiner E (2002) Persistent organic pollutants in Detroit River suspended sediments: polychlorinated dibenzo-p-dioxins and dibenzofurans, dioxin-like polychlorinated biphenyls and polychlorinated naphthalenes. Chemosphere 49:111-120

Marvin C, Williams D, Kuntz K, Klawunn P, Backus S, Kolic T, Lucaciu C, Macpherson K, Reiner E, Erie F (2007) Temporal trends in polychlorinated dibenzo-p-dioxins and dibenzofurans, dioxin-like PCBs, and polybrominateddiphenyl ethers in Niagara river suspended sediments. Chemosphere 67:1808-1815

Moon H-B, Yoon S-P, Jung R-H, Choi M (2008) Wastewater treatment plants (WWTPs) as a source of sediment contamination by toxic organic pollutants and fecal sterols in a semienclosed bay in Korea. Chemosphere 73:880-889

Paasivirta J, Sinkkonen SI (2009) Environmentally relevant properties of All 209 polychlorinated biphenyl congeners for modeling their fate in different natural and climatic conditions. J Chem Eng Data 54:1189-1213

Robrock KR, Korytár P (2008) Pathways for the anaerobic microbial debromination of polybrominated diphenyl ethers. Environ Sci Technol 42:2845-2852

Safe S (1992) Development, validation and limitations of toxic equivalency factors. Chemosphere 25(1-2):61-64

Salvadó J, Grimalt J, López J, Durrieu de Madron X, Heussner S, Canals M (2012) Transformation of PBDE mixtures during sediment transport and resuspension in marine environments (Gulf of Lion, NW Mediterranean Sea). Environ Pollut 168:87-95

Shen L, Gewurtz SB, Reiner EJ, Macpherson KA, Kolic TM, Khurana V, Helm PA, Howell ET, Burniston DA, Brindle ID, Marvin CH (2009) Occurrence and sources of polychlorinated dibenzo-pdioxins, dibenzofurans and dioxin-like polychlorinated biphenyls in surficial sediments of Lakes Superior and Huron. Environ Pollut 157:1210-1218

Song W, Ford JC, Buckley DR, Rockne KJ (2004) Polybrominated diphenyl ethers in the sediments of the Great Lakes. 1. Lake superior. Environ Sci Technol 38:3286-3293

Torkaz J III, Ahn M, Leng J, Filley T, Nies L (2008) Reductive debromination of polybrominated diphenyl ethers in anaerobic sediment and a biomimetic system. Environ Sci Technol 42:1157-1164

USEPA (2011) Estimation Programs Interface Suite ${ }^{\mathrm{TM}}$ for Microsoft ${ }^{\circledR}$ Windows, v 4.10. United States Environmental Protection Agency, Washington, DC, USA

Van den Berg M, Birnbaum L, Bosveld AT, Brunstrom B, Cook P, Feeley M, Giesy JP, Hanberg A, Hasegawa R, Kennedy SW, Kubiak T, Larsen JC, Van Leeuwen FXR, Liem AKD, Nolt C, Peterson RE, Poellinger L, Safe S, Schrenk D, Tillitt D, Tsykline M, Younes M, Warn F, Zacharewski T (1998) Toxic equivalency factors (TEFs) for PCBs, PCDDs, PCDFs for humans and wildlife. Environ Health Perspect 106:775-792

Vonderheide A, Mueller K, Meija J, Welsh GL (2008) Polybrominated diphenyl ethers: causes for concern and knowledge gaps regarding environmental distribution, fate and toxicity. Sci Total Environ 400:425-436

Zheng GJ, Martin M, Richardson BJ, Yu H, Liu Y, Zhou C, Li J, Hu G, Lam MHW, Lam PKS (2004) Concentrations of polybrominated diphenyl ethers (PBDEs) in Pearl River Delta sediments. Mar Pollut Bull 49:520-524

Zhu LN, Hites RA, Erie L (2004) Temporal trends and spatial distributions of brominated flame retardants in archived fishes from the Great Lakes. Environ Sci Technol 38:2779-2784 